\title{
Ethnologies
}

\section{Di sak na pou di}

\section{Retour aux coeurs d'une ethnographie du maloya}

\section{Benjamin Lagarde}

Volume 40, numéro 1, 2018

URI : https://id.erudit.org/iderudit/1054315ar

DOI : https://doi.org/10.7202/1054315ar

Aller au sommaire du numéro

Éditeur(s)

Association Canadienne d'Ethnologie et de Folklore

ISSN

1481-5974 (imprimé)

1708-0401 (numérique)

Découvrir la revue

\section{Citer cette note}

Lagarde, B. (2018). Di sak na pou di : retour aux coeurs d'une ethnographie du maloya. Ethnologies, 40(1), 139-158. https://doi.org/10.7202/1054315ar

\section{Résumé de l'article}

Tout comme la musique, phénomène circulatoire catégorisé par l'emprunt, le mélange autant que la définition d'esthétiques et d'univers sémantiques fixes, les sociétés créoles présentent l'avantage anthropologique de mettre en relief la complexité des notions d'identité et de culture. Remarquons d'ailleurs que la première sert le plus souvent d'emblème reconnu des secondes dans notre monde hyper-moderne consommateur de biens culturels déterritorialisés. En tant que contribution réflexive à l'étude de la société réunionnaise s'appuyant sur l'expérience d'un étudiant ayant dédié son doctorat à la musique dite " traditionnelle » de cette île française, cet article propose un retour sur quelques présupposés et biais subjectifs ayant orienté une recherche marquée par le sceau de la marginalité, de la déviance et de la résistance aux discours officiels. Après énumération d'éléments autobio-musico-graphiques, plusieurs faits de terrain éclairent la sorte de mécanisme d'acquisition culturelle par lequel l'individu se trouve engagé dans le processus de créolisation réunionnaise.
Ce document est protégé par la loi sur le droit d'auteur. L'utilisation des services d’Érudit (y compris la reproduction) est assujettie à sa politique d'utilisation que vous pouvez consulter en ligne.

https://apropos.erudit.org/fr/usagers/politique-dutilisation/ 


\section{SAK NA POU DI}

Retour aux cœurs d'une ethnographie du maloya

\section{Benjamin Lagarde \\ Chercheur associé à l'IDEMEC}

Nous haïssons l'ethnographie : chaque fois que, s'achevant ailleurs, elle ne fertilise pas le vœu dramatique de la relation. La méfiance que nous lui vouons ne provient pas du déplaisir d'être regardés, mais de l'obscur ressentiment de ne pas voir à notre tour.

\section{Édouard Glissant, L'intention poétique}

Il y a dix ans, j'achevai mon terrain réunionnais ${ }^{1}$. Celui-ci avait pour but de documenter une pratique créole réputée " traditionnelle » ainsi que de rendre saillants les liens susceptibles d'exister entre certains aspects musicologiques la définissant au premier chef et les dynamiques sociales relatives à un espace culturel qu'elle participe également à délimiter. Prise dans un « maillage » à la fois vaste et resserré, une telle recherche ne pouvait qu'être multi-située et la fréquentation du maloya tendre pour moi à une certaine permanence du fait de l'attachement que cette entreprise ne pouvait manquer d'impliquer (Latour 1996). Car, en effet, capable de circuler avec une aisance qui lui est propre - ce que ne font que relayer et décupler les technologies numériques -, la musique en tant que " fait musical total » ne se scrute qu'au moyen d'un constant aller-retour entre l'immensité extérieure, plus ou moins objectivable, et notre intériorité

1. Après un terrain de maîtrise réalisé dans l'île en 2000 ( 8 février- 8 mai) et un autre pour mon Master 2 en 2005 (12 janvier-31 mars), ont suivi trois terrains de doctorat (18 octobre-21 décembre 2005 ; 24 septembre-23 décembre 2006 ; 24 septembre 2007-7 janvier 2008). Les choses auraient été probablement tout autres si je n'avais pas reçu une bourse doctorale et occupé la charge universitaire de moniteur m'ayant imposé ces allers-retours. Subventionné par mon laboratoire, l'IDEMEC (UMR 7307, Aix-Marseille Université), un sixième et dernier voyage de deux semaines eut lieu en mai 2009 à l'occasion d'un colloque (Lagarde 2011). 
la plus subjective (Green 2000 ; 2003 : 223). Bien qu'ayant d'une part suivi Roger Bastide, pionnier de la recherche en sociétés créoles, lorsqu'il invitait, et ce dès les années 1940 et 1950, à penser qu'un objet d'étude se « choisit pour des raisons qui s'enracinent dans votre subjectivité et peuvent plonger parfois jusqu'aux structures de l'inconscient » (Morin 1975), et ayant d'autre part mené mon enquête avec certaines précautions réflexives m'ayant permis, j'ose le penser, de ne pas écrire mon doctorat sur le «pilote automatique »(Ghasarian 1998 ; voir aussi Jamin 1985), force est d'admettre que l'exercice réflexif demeure périlleux. Aussi, tout en conservant une certaine prudence face à mes propres épanchements, c'est-à-dire en mentionnant le «minimum d'explication nécessaire » et sans exalter ma subjectivité (Olivier de Sardan 2000)², je tâcherai d'éviter de produire « une ethnographie des confessions » qui resterait triviale une fois parée du label « réflexivité » et signifierait « simplement une introspection psychologisante et autocentrée du narrateur » (Ghasarian 2002 : 14).

Bénéficiant de plusieurs années de recul depuis la soutenance de mon doctorat ainsi que de la distanciation que me procure à l'endroit des sociétés créoles, autant que de la métropole française, le fait de vivre au Québec depuis 2010, je voudrais à la fois essayer de répondre aux attentes d'un Glissant, rappellées en exergue, et de suivre le mouvement du maloya luimême, chant réunionnais le plus souvent à répons dont le mobile profond semble d'ailleurs tenir au sens qu'on lui donne parfois : « en malgache maloy aho" veut dire parler, dégoiser, dire ce qu'on a à dire $»^{3}$. En plaçant mon propos dans l'axe de l'expression kréol lui servant de titre ${ }^{4}$, je consignerai ici quelques éléments (prénotions, socialisation secondaire, événements de

2. Point qu'on nuancera avec Leiris dont l'œuvre énonce précisément cette sorte de Règle du jeu selon laquelle ne peut être atteinte l'objectivité, voire l'universel, qu'au prix d'une subjectivité assumée ou d'une « ethnologie de soi », réfléchie à partir du miroitement (au sens du miroir, ce genre littéraire médiéval repris par Leiris dans son Miroir de la tauromachie ainsi que par ses éditeurs posthumes, 1996) en soi de choses au préalable extérieures.

3. Gaston Hoareau dans son « Explication succincte du maloya » (voir discographie, Bourbon maloya, 1999 : 8). Les éditions ultérieures de cette anthologie notent «maloya aho ».

4. «Di sak na po di » (littéralement : « dire ce qu'il y a à dire » ou ce « qu'il faut dire ») est le titre de plusieurs tribunes locales, tant écrites que radiophoniques. Choisissant de laisser transparaître chaque langue dans l'autre, le kréol écrit ici s'écarte parfois des différentes graphies existantes. Fidèle à la liberté prise par mes informateurs en la matière, notamment dans leurs livrets de disques, ce choix personnel condense et illustre les considérations étymologiques, phonétiques et ethnographiques à partir desquelles s'est élaborée mon interprétation de la réalité réunionnaise. 
terrain, etc.) à partir desquels s'est définie ma relation, y compris analytique, à cette musique, à ses acteurs et à leur île $e^{5}$. Ceci permettra de souligner plusieurs mécanismes à l'œuvre à La Réunion, dont certains touchent au fondement de l'expérience de traduction culturelle sur laquelle reposent tout autant le projet ethnographique, le fait créole, historique comme contemporain, ou encore l'écoute musicale.

\section{Éléments d'autobio-musico-graphie}

Parmi l'ensemble des choix et des déterminismes ayant façonné le jeune homme de 21 ans que j'étais au moment où il fallut décider d'un terrain de maîtrise d'ethnologie, domine l'influence de deux de mes professeurs. La rencontre du premier - c'est ainsi du moins que je me le représente aujourd'hui - me fit quitter la filière scientifique suivie par ma famille nucléaire (mes parents, ma sœur et mes deux frères). Ce «professeur d'occitan » réveilla chez moi en classe de seconde un questionnement ancien pour les faits de culture qui s'était, paradoxalement, ancré à la fois dans un passé monumental, prestigieux mais distant, et dans mon vécu immédiat. Né en 1977 à Figeac $^{6}$, ville dont Jean-François Champollion reste à mes yeux la figure majeure, les mythologies anciennes et leurs langues, mortes comme vives, m'avaient en effet très tôt fasciné. Inversement, sans aucune mise en scène culturelle et dans un réel silence, à mesure que je visitai, presque chaque dimanche jusqu'à mon inscription en sociologie, mes " grands-mères » (à savoir mon arrière-grand-mère maternelle ${ }^{7}$ et sa fille, toutes deux filles uniques nées respectivement en 1899 et 1921) dans leur village aveyronnais, je perçus (certes de manière longtemps inarticulée, laquelle tenait peut-être à l'absence de leurs défunts maris, agriculteur et boulanger) la précarité des cultures paysannes, orales, qu'accélérait la prodigieuse ascension sociale réalisée durant les années 1970-1980 par la cohorte des baby boomers. Ce génocide culturel larvé ${ }^{8}$ transparaissait

5. Mes interventions à la Journée des doctorants de l'IDEMEC (25 avril 2008) ainsi que dans un cours d'initiation à l'enquête de terrain donné par Monique Desroches à l'Université de Montréal (22 novembre 2011) servirent de préliminaires à cette contribution. Celle-ci bénéficia également de la relecture qu'en fit Jean-Luc Bonniol et pour laquelle je le remercie à nouveau.

6. J'ai décrit la façon dont cette ville a structuré mon expérience du monde dans Lagarde (2004).

7. Au sujet de laquelle correspond tout à fait la description que donnait le cinéaste Georges Rouquier de sa propre grand-mère rouergate ( « petite femme sèche, mais pleine d'autorité ») dans son autobiographie inédite lisible en partie au musée de Goutrens.

8. En 1864, plus de 90\% du département ne parlait pas français (Boyer 1991 : 35). 
dans l'omniprésence d'ensembles bâtis autrefois prospères mais à présent abandonnés et repris par la végétation comme à chaque fois que sonnait le glas pour une des connaissances venues encore tout récemment parler « patois » avec mon arrière-grand-mère dans l'épicerie qu'elle tint jusqu'à sa mort à 102 ans. A leur manière, mes parents, pharmaciens et biologistes demeurant " en ville », furent acteurs de ce bouleversement en étant, par exemple, les premiers de leurs lignées à employer une domestique de jour. D'origine rurale, à peine plus jeune que ma grand-mère et comme elle rémunérée pour faire des ménages, "Madame Laborie » (nom désignant justement l'habitat rural occitan) s'occupa de moi dès ma naissance. Un peu à la manière dont l'aurait peut-être fait une nourrice de couleur de l'enfant de ses maîtres...

Du fait de mon attachement pour cette histoire à lire entre les pierres et les silences - quelques espiègleries formulées à l'endroit du Progrès ou de la Culture aussi ${ }^{9}$-, je ne pus adhérer au chahut inégalable que mes amis de classe réservaient chaque semaine à ce professeur s'essayant à faire (re) vivre en nous ce que je conçois comme notre arrière-langue. Bien qu'il fût incomparablement plus permissif que nos autres enseignants, dont certains étaient membres du clergé, son cours fut peut-être d'emblée récusé du fait de la honte culturelle qui, me semble-t-il, était alors associé à l'héritage paysan. Pour la même raison, je ne pus souscrire à ces racismes plus ou moins ordinaires conduisant les Lotois (avec lesquels je ne partageais que le lieu de vie) à dénigrer les Aveyronnais. Victor, l'enfant sauvage, semblerait presque avoir durablement alimenté la représentation que se font leurs voisins de ces « péteux putrides » (Le Roy Ladurie 1997) ${ }^{10}$ ne connaissant de la civilisation que ses tous premiers stades. Or mes allées et venues de part et d'autre de la frontière liquide dessinée par les courbes du Lot m'ont inculqué combien les gens n'y sont pas si différents, comme l'attestent par exemple les solutions matérielles qu'ils apportèrent au fil du temps ${ }^{11}$ aux

9. «Plus on est intelligent, plus on est bête » est un des aphorismes employés par mes aînées à l'égard notamment des industriels et politiciens ayant précipité le passage d'un monde rural à un autre. L'étude impressionniste de Benoist (1984) décrit ce bouleversement pour La Réunion.

10. On notera cet effet de balancier, bien connu en contexte créole, par lequel l'auteur renverse ce stigmate en évoquant l'autarcie et « l'involution » d'une région pauvre qui, durant près d'un millénaire, « s'enfonce graduellement dans son isolationnisme $[\ldots]$ se perfectionne et $[. .$.$] s'affine, comme s'affinerait un roquefort » et où l'on$ parle l'« un des plus purs langages de la communauté occitane ».

11. Une nouvelle datation fait remonter l'occupation des grottes de notre région, non plus à 38000 ans, mais à 175600 ans av. J.-C. (http://www2.cnrs.fr/presse/ communique/4563.htm, site consulté le $1^{\text {er }}$ février 2018). 
problèmes posés par leur milieu. En outre, dans cette Guyenne d'Ancien Régime (Guiana en occitan), Figeac se situant à l'exact carrefour de plusieurs régions naturelles (Causse du Quercy, Limargue, Ségala, Rouergue) en débordant elles-mêmes d'autres, administratives cette fois (Lot, Aveyron, Cantal, Tarn...), n'y avais-je pas appris à percevoir, sur quelques kilomètres, l'étalement de traits culturels et la manière dont ils s'estompent de proche en proche selon un continuum à plusieurs variables ? Malgré le désert relatif du Larzac, la route vers Montpellier (d'où est originaire mon père et où vivaient ses parents, eux-mêmes de lignées de pêcheurs audois et d'agriculteurs ariégeois) ou encore les voyages effectués en Europe dans notre camping car familial vinrent confirmer ce constat continuiste que je tins dès lors pour extensible.

Mon entrée à l'Université Toulouse-Le Mirail correspondit à une seconde naissance tant la nouveauté touchait à peu près tous les aspects de ma vie. S'attachant à concevoir l'existence de sous-ensembles sociaux étanches et poreux à la fois, la sociologie pointait aussi la difficulté consistant à parvenir à s'inscrire pleinement dans une culture marxisante en provenant d'un milieu commerçant et " libéral » ${ }^{12}$ étranger aux lettres, aux musées, à la scolastique. N'ayant aucun capital adapté, tant « social » que «culturel », j'engageai toute ma bonne volonté au service d'un projet scientifique dont il fallut assimiler le langage spécifique. Les bibliothèques m'offrirent cette chance et la part inconsciente de mon parcours trouva rapidement matière à identification chez un Goffman ou un Bourdieu. Juif ukrainien des plaines canadiennes pour l'un, fils de facteur béarnais pour l'autre, n'avaient-ils pas eux-mêmes été en situation de transit (Winkin 1988 ; Bourdieu 2004) ? Leur attention minutieuse pour la vie quotidienne résonna tout particulièrement en moi du fait de l'aspect microscopique lié à la conception de l'œuvre de science que j'héritai de mes parents ainsi que de ma prétention à appartenir à un nouvel univers social marqué par une certaine ouverture tant géographique que sociale et culturelle.

Toutefois, précisément, la véritable flamme ne fut allumée qu'avec le cours intitulé «Relations interethniques » que donnait Pierre-Jacques Rojtman. Nous n'étions que cinq à profiter du savoir encyclopédique d'un maître accompagnant toujours, comme cela n'aurait déjà plus dû se faire, ses digressions de nouvelles bouffées de cigarette. Ayant été - ce que les manuels oublient - le premier traducteur français de l'École de Chicago, il nous initiait à l'épistémologie, la philosophie, l'ethnologie, la sociolinguistique

12. Mes parents étaient membres de la catégorie socioprofessionnelle « cadres et professions libérales ». 
et la psychosociologie afin de construire un objet d'étude éminemment hybride et urbain. C'est à lui que je dois de m'être orienté vers les sociétés créoles et les cours donnés à Aix-en-Provence. C'est aussi à lui que je dois la confirmation du pressentiment que les choses marginales occupent le centre, ce que montrent notamment les mécanismes de régulation sociale à l'œuvre dans le champ esthétique dont la fête, souvent carnavalesque, musicale et ayant atteint certaines apogées en terres créoles, reste l'exemple idéal.

Ces préoccupations faisaient ainsi le lien avec d'autres ayant germé en moi au contact des formes musicales les plus diverses. "L'oreille n'ayant pas de paupière » selon Pascal Quignard, mes frères (aînés de quatre et huit ans) furent d'emblée déterminants en relayant jusqu'à moi les musiques anti-radiophoniques ${ }^{13}$ d'artistes dits « indépendants " pris dans les remous du punk ${ }^{14}$. Ils firent de moi, bien avant l'âge de raison, un récepteur averti de quelques alors obscurs groupes anglais. Le fait qu'ils ne partageaient pourtant pas exactement les mêmes aficion (disons New Order et The Smiths pour l'un, Joy Division et The Cure pour l'autre) me demandait de les comprendre tous deux et de forger mes propres goûts (A Certain Ratio, Durutti Column, Wire...). Je fis de même à partir des musiques de notre sœur aînée (qui me réconcilia en un sens avec des groupes plus mainstream tels « les » Doors ou U2) ou de nos parents, dont la discothèque allait des Beatles au New Age, de la soul et du Music-hall à la musique classique.

Après quelques années de piano et clavecin classique vint, avec la vague grunge, le moment de prendre la guitare, de composer et fonder un groupe. Après 4 ans de répétitions et de concerts celui-ci se défit alors que chacun des membres partîmes étudier à l'extérieur du département. Je garde une impression d'inachevé du fait que, n'y ayant pas prétendu alors, notre musique ne parvint jamais au stade de l'enregistrement un tant soit peu professionnel. Remplaçant cette implication dans un collectif musical par un intérêt plus théorique, je choisis l'ethnomusicologie comme sujet de mémoire de licence. Par ce croisement disciplinaire, je conservai ma passion musicale et réduisis l'angoisse de la méthode ethnologique en pensant, le

13. John Peel français, Bernard Lenoir, proposait très sociologiquement, de la « musique pas comme les autres".

14. On notera combien cette scène dite «New Wave ", s'évertuant à démontrer, selon Christophe Conte, "l'impossible articulation entre l'art et le commerce, tous ces groupes se voulant en effet comme les derniers Mohicans d'une certaine utopie née à l'époque du psychédélisme », engendra une multiplicité de formes innovantes à mille lieux des caricatures « no future » (Les Inrockuptibles 2016 : 26-27). Rappelons que l'ire du reggae irriguait aussi ce mouvement de manière synchrone. 
cas échéant, pouvoir justifier des observations abstraites par un matériel un tant soit peu objectif ${ }^{15}$. Entamant alors une histoire d'amour de sept ans avec une Franco-brésilienne, le sujet de ma maîtrise s'arrêta sur le maloya suite au déménagement à La Réunion d'un ami d'enfance, rasta ayant été le multi-instrumentiste de notre groupe.

Bénéficiant d'une marge de manœuvre appréciable du fait que mes parents financeraient mon voyage et que mon directeur, Jean-Luc Bonniol, me laissait libre de cheminer à partir des abondantes documentations alors disponibles à l'Institut d'études créoles et francophones (où Robert Chaudenson m'aiguilla quelque peu) et au Centre d'études et de recherches sur les sociétés de l'océan Indien (dirigé par Hubert Gerbeau), j'alimentai inconsciemment l'écoute approfondie d'une culture musicale minorée par le désir de me comprendre et, peut-être, au moyen de l'écrit, de faire entendre ma propre voix. Ce désir, qui est à l'origine de ma pratique poétique et de mes compositions, est entré en résonance avec un terrain créole où dominent les questions de déviances, de détournement et de résistance, notamment artistique. Associant le surmoi monolithique du pouvoir colonial et postcolonial avec la grande Culture indifférente aux expressions régionales et populaires, je m'engageai dans un marronnage scientifique (au sein des sciences, celles dites humaines sont, en un sens, déjà marginales mais ne semblant pas avoir suffisamment saisi la portée du champ créole il s'agissait de les détourner quelque peu à leur tout).

\section{De quelques prémisses distinctives et de leurs résultats}

Ainsi, malgré un certain parti pris pour les laissés-pour-compte, la leçon distinctive et résolument minoritaire de mes frères orienta mon entrée dans la discographie maloyaine en me conduisant, par exemple, à rester prudent vis-à-vis des artistes les plus en vue dont plusieurs, venus des scènes « traditionnelles » et " électriques », affichaient volontiers leurs liens avec le Parti communiste réunionnais (PCR). Monopolisant généralement le discours entourant le maloya, les tropes véhiculés par ce foyer légitimant (qu'on ne saurait envisager sans relation à d'autres) résistèrent effectivement mal à une investigation des archives. La pierre angulaire de cette idéologie, à savoir l'interdiction par les autorités de jouer cette musique ${ }^{16}$, toucha en réalité les seuls musiciens militant à ce

15. En effet, je ne souhaitais pas reconduire le « syndrome McAllester » consistant à disjoindre analyses musicales et sociales (Boilès et Nattiez 1977 ; Desroches 1996).

16. Interdiction qu'aurait précisément bravée le PCR : «At the founding Congress of the Réunionnais Communist Party, the band of Firmin Viry, a descendant of 
parti autonomiste créé en 1959. Deux ans avant cela, le journal Le Peuple, très aligné sur la politique métropolitaine, pouvait programmer un « gala folklorique » à Saint-Denis dans lequel joua Augustin Mirza - que Firmin Viry (1999) présente comme son mentor. Son concert fut de plus diffusé dans toute l'île en direct à la radio ${ }^{17}$. D'autres déformations résultèrent de la rencontre qu'effectuèrent des membres de classes sociales différentes au nom de la lutte desdites classes. L'autonomie politique devant s'appuyer sur une culture populaire authentique ${ }^{18}$, plusieurs idéologues du parti parlèrent alors littéralement les prolétaires ruraux ${ }^{19}$. Confrontés à des pratiques des plus bigarrées et hétérogènes, ils effectuèrent, peut-être bien malgré eux, certaines sélections qui conduisirent à remanier cette tradition qu'il s'agissait pourtant de « mettre en l'air » à partir des ténèbres de l'histoire servile. Outre la tentative de définition de l'instrumentarium type que propose Viry dans les extraits d'entretiens rendus publics sur le premier disque de maloya ${ }^{20}$, le caractère doloriste et misérabiliste associé à ces chants, notamment par Alain Lorraine ${ }^{21}$, semble avoir accentué la valorisation du mode mineur, de tempi lents et d'un timbre sourd du roulèr (tambour emblématique du genre) ; traits qui servirent à distinguer efficacement ce genre du séga, l'autre musique locale considérée alors comme légère et acquise aux canons coloniaux (Desrosiers 1996). Or, loin d'être seulement une complainte, d'autres musiciens nés avant la départementalisation - je

slaves, performed a maloya for the first time in public » (Vergès 1999 : 310). On pourra se demander légitimement de quel public il est ici question...

17. Comme me l'apprit le poète Boris Gamaléya à son domicile le 26 décembre 2006.

18. «Je pense que le dynamisme du Maloya tient au fait qu'il est une forme d'expression musicale et sociale authentique de la Réunion : une fois remonté à la surface, il a pu être réapproprié par une grande partie du peuple réunionnais. Le Maloya c'est une chronique sociale (...) Notre contribution à la diffusion publique du Maloya, après une longue période de clandestinité et de censure, est un exemple parmi tant d'autres de l'action du PCR pour l'affirmation de l'identité réunionnaise » (Vergès et Croisier, 1993 : 141).

19. Outre son analyse de la sorcellerie et son caractère théorique quant à l'enquête, le propos de Jeanne Favret-Saada à l'endroit des « arriérés » du Bocage normand est ici des plus précieux tant il propose de passer de l'autre côté du miroir sociologique et ouvre aux phénomènes de double entendre.

20. Tentative par ailleurs infirmée par sa discographie qui ne sollicite que deux fois le bob : sur "Cette année quelle belle année », titre chanté par Céline Viry pour Bourbon Maloya (1999, 2 : \#16), et «Valé-valé prété-moi vo fuzi » (France : une anthologie des musiques traditionnelles, $2010: \# 1)$.

21. Venant de « découvrir » le maloya chez Viry, cet intellectuel militant écrivait : « [i]l est biblique, ce chanteur. Il est dans l'exode. Et cela fait mal » (Témoignages chrétiens de La Réunion n 98, 1975 : 8). 
pense à Henri « Ti Baguette » Lagarrigue (1916-2002) ou Jean-Baptiste « Batis Kabaré » Jouano (1920-1980) - considéraient aussi le maloya comme un réel amusement qu'on chantait notamment au Mardi gras, sur un mode majeur et à rythme soutenu. On peut aussi se demander si cette sélection culturelle n'a pas précipité la progressive disparition du kabaré - l'ancien nom donné au maloya autour de Saint-Louis ? Celui-ci comprenait un prélude «pleuré », chanté par un soliste reprenant souvent d'anciennes romances françaises, " cassant » ensuite en « maloya » pour laisser place à la danse, « un cavalier, une cavalière » nous disent les anciens, et au tuilage de chœurs chantant en kréol.

Outre ces distorsions inconscientes induites par la mise en relation de milieux sociologiques et culturels vécus au préalable comme distincts, d'autres, aux apparences plus conscientes, sont aussi à souligner. L'une d'elles concerne le tabou qu'est le communautarisme pour la République. Porté également par le PCR, il qui amena logiquement ce dernier à tenter de débrancher le maloya de sa "racine kaf ${ }^{22}$. L'enjeu était d'autant plus de taille qu'au moment (les années 1970) où le parti « dépistait » et formait des groupes de maloya ${ }^{23}$, nombre de porteurs de cette tradition étaient des pratiquants des "services kabaré », ces cultes rendant hommage au son de cette musique à leurs lignées ancestrales malgaches et/ou africaines. Au lendemain de l'inscription du maloya au Patrimoine culturel immatériel, Viry déclarait par exemple : « [1]e maloya c'est populaire, c'est l'inspiration du peuple, mais le kabaré c'est sacré, ce n'est pas du maloya » (Le Quotidien, 2 octobre 2009). Ce faisant il répétait cette tendance à laïciser le maloya que l'on perçoit déjà dans la fabrique de la fête nationale du 20 décembre dans les organes de presse du parti. Dans « 20 désanm bann marmay » (Bourbon maloya, 3 : \#22), conte extrait des Histoires Ti kok écrites par le Père Fontaine (parfois aidé de Danyèl Waro) et adaptées avant sa mort (1984) pour la radio militante Pikan, le « premier grand homme culturel réunionnais de tous les temps » confond des éléments rituels catholiques, hindous et animistes afin de produire, non sans paternalisme, cette «identité réunionnaise » dont, précisément, il « vulgarise auprès de la population les

22. Rasin Kaf est une association œuvrant actuellement pour la réhabilitation de l'image du Cafre, le Noir réunionnais ; voir Nicole (1996). L'historien Sudel Fuma estimait que près de $80 \%$ des Réunionnais auraient un ancêtre esclave (Courrier des lecteurs du journal Témoignages du $1^{\text {er }}$ décembre 2009). Avec l'ethnologue Jean Poirier, il décrivit la persistante dévalorisation de cette composante culturelle dans l'île (Poirier et Fuma 2004).

23. Propos du père Christian Fontaine (Témoignages chrétiens de La Réunion, n 119 , $1975: 60)$. 
premières réflexions $»^{24}$.

Toutefois, ce projet politico-esthétique - dont la déconstruction, par ailleurs rarement proposée (voir Léger 2001 ; Samson 2006), ne peut que bénéficier d'une analyse ethnomusicologique - ne s'est jamais réellement réalisé. Des artistes tels Viry ou Waro, lequel exemplifie «l'ethos de liberté » caractérisant les Petits-Blancs (Ottino 1999) dans son approche d'une tradition musicale qu'il ne connut que sur le tard, n'ont effectivement pu réussir à s'extraire d'un contexte à forte assignation identitaire. Pour situationnelles qu'elles soient, leurs affinités avec l'hindouisme créole n'activent-elles pas, par exemple, ce communautarisme que leur parole publique décrie la majeure partie du temps?

Cette distance de principe qui m'écarta également de " médiateurs » appartenant aux sphères de décision de l'industrie musicale (journaux, maisons de disque, radio, Pôle régional des musiques actuelles, etc.) et des tenants de ce maloya folklorique servant de repoussoir aux communistes ${ }^{25}$, ne doit cependant pas cacher l'impact qu'eurent sur moi ces deux maloyèr. Par exemple, outre son volet musical, l'œuvre warotienne demeure un modèle de marronnage où poésie et réflexion fusionnent pour critiquer notre capitalisme tardif depuis une de ces îles à sucre où il fourbit ses premières armes. Séduit, comme tant d'autres ${ }^{26}$, notamment par son $(\mathrm{r})$ appel à l'agriculture ${ }^{27}$, j'ai vu en lui ce pont « fièrement bâtard » capable de relier, à tout le moins symboliquement, les opacités sociales qui ne pouvait que m'atteindre en plein cœur.

24. Voir les pages 19 et 34 du livret (amputé par la suite) de la première édition de Bourbon maloya.

25. M'étant toutefois également appuyé sur sa discographie, incomparablement mieux diffusée que celle militante jusqu'au milieu des années 1990, je peux affirmer qu'à ne pas entendre ce second mode d'invention de la tradition du maloya, on s'empêche de comprendre la genèse des représentations de l'identité musicale du Kaf, voire du Réunionnais, à l'œuvre chez tant d'artistes contemporains.

26. Tel ce journaliste des Inrockuptibles écrivant sur l'emballage de Kabar, son dernier disque live : " [q]uiconque a assisté à un concert de Danyèl Waro chérit vraisemblablement ce jour où il a découvert l'un des plus grands chanteurs vivants ». La révolution qu'il induisit dans le champ maloyain évoque en un sens celle d'un Manet (Bourdieu 2013).

27. Son aspect décisif en matière de postcolonialité s'entend chez lui de «Adékalom », daté de 1980 (Waro 2013 : \#7), à « Tinn tout » (Waro 2013 : \#9) où ce fils de planteur militant cite une parole d'Ho-Chi-Minh qui lui est chère : «pèp i plant pa son dori li krèv! » - « un peuple qui ne plante pas son manger ne survit pas! » (ma traduction). 


\section{D'une familiarité de principe au principe de la famille}

Toutefois, une empathie plus profonde encore me lia à d'autres musiciens dont je partageai un temps l'existence et les représentations. Trois ans après avoir obtenu ma maîtrise, en même temps que ses films documentant les cultes créoles dans lesquels on joue du maloya, je rencontrai Françoise Dumas-Champion à la salle Jean Rouch du Musée de l'Homme. Encouragé par la lecture de ses articles et retrouvant chez elle une passion pour le vaste chantier de la question kaf, je m'inscrivis en Master d'anthropologie dès la rentrée suivante. Le premier sèrvis auquel j'assistai fut celui adressé à Emmanuel « Granmoun Baba » Salomon (1916-2004) par sa veuve 40 jours après son décès. Ma recherche s'inscrivit dans un moment particulier de l'histoire culturelle insulaire : celui du Renouveau malgache. Il faisait écho à celui qu'avait connu le milieu indien dans les années 1970-1980 et qu'avaient abondement étudié les anthropologues. Aussi, comme happé par la fascination qu'elle n'avait manqué d'exercer tant sur les Créoles que sur leurs observateurs, j'empruntai à mon tour la voie du sacré. Tout en sachant que ma recherche, limitée dans le temps, dépendrait de «vraies rencontres », fussent-elles brouillées de malentendus (Clifford 1996 : 94), et que la compréhension que je visai, à titre personnel avant tout, des phénomènes culturels au moyen de la musique dépendrait à la fois d'une expérience subjective et de ma participation au « discours indigène », je ne pris conscience que bien après d'un « enclicage »(Olivier de Sardan 1995) qui avait déjà commencé à me lier à cette culture de la pauvreté qui pour être en l'occurrence issue de la Plantation (Wolff 1991) n'en partageait pas moins ses structures avec d'autres, notamment européennes (Hoggart 1991) dont certaines rappelaient avec une exactitude confondante le vécu rural de mes grands-mères.

Étant alors ce « jeune [...] petit bonhomme curieux que décrit Jean Benoist, qui fait n'importe quoi, qui loge n'importe où » (Lévy $2000: 139$ ), tissant des liens dans plusieurs communes, je suivis bientôt de près les « entraînements » d'un groupe destiné à animer des sèrvis. Mère de deux musiciens auxquels j'avais présenté mon projet dès notre rencontre, je rencontrai en février 2005 Madame Yvonne ${ }^{28}$. Elle proposa de m’héberger sur une base régulière. Bien que située en centre-ville de Saint-André et malgré l'eau coulant du toit à chacun de ces déluges qui ne sont que de simples averses sur cette côte au vent, sa « case en bois sous tôle » d'un autre temps n'avait comme raccord à l'eau de ville qu'un long tuyau d'arrosage au fil des usages duquel pouvaient se lire les préoccupations de la maisonnée.

28. Nom fictif. 
Outre son usage pour la cuisine, tâche hautement valorisée, le ménage et la lessive, faite à la main sur les galets de la cour, la puissance purificatrice de l'humble liquide y garantit la bonne cohabitation entre cette famille et tout un ensemble d' « esprits ». Notamment au moyen du nettoyage quotidien de la case et de bains pris par nous tous après macération d'herbes et de «tisanes ». Étant devinèr et « travaillant » avec ses esprits dans ses consultations $^{29}$, Madame Yvonne me mit ainsi au pli d'une vie extrêmement ordonnée dans laquelle le respect d'obligations autant que d'interdits associés à la nourriture, aux activités, voire, durant les fréquents « carêmes », aux pensées (dont les plus polluantes ont trait au sexe) introduit à un univers où s'emmêlent réalité tangible et réalité invisible. N'étant accessible que les « jours malgaches » (soit les mardi, jeudi et samedi, consacrés par cette famille à l'une de ses filiations, l'autre étant malbar $^{30}$ ), le maloya y participe de façon exemplaire à la régulation des relations mettant les croyants aux prises avec des forces pouvant favoriser comme empêcher leur existence - existence par ailleurs semée d'embûches et de conflits, ce dont l'histoire de cette famille témoignait déjà tragiquement.

À mesure que je "gagnais le goût », fortement pimenté, d'une vie évoquant ce « temps longtemps » à partir duquel se définissent ici les critères de l'efficacité symbolique des rituels autant que du « maloya traditionnel » lui-même, la causalité propre à cette cosmogonie accentua son emprise sur moi. Donnant mon «propre désir à interpréter » au devin (Favret-Saada 2004 : 47), j'entrai également dans un cycle de remerciements rituels de trois ans (qui correspondit à mon monitorat à l'Université Aix-Marseille). L'exercice consistant à se décentrer pour (re)voir avec les yeux d'une autre culture emporta de plus en plus l'interprétation que je faisais d'événements en apparence aussi divers et anodins que le fait d'avoir effacé, sans le vouloir, les fichiers «sales » du GSM d'un des fils de la maison la veille du carême préparant au service annuel, ou encore l'impossibilité de voir imprimer en couverture puis en couleur le tableau de Jimmy Cambona que j'avais proposé pour illustrer L'univers du maloya (Samson, Lagarde et Marimoutou 2008 : $154)^{31}$. Il en alla de même de l'intention que je plaçais dans mes actions

29. Ainsi qu'à partir de nombreux autres outils parmi lesquels sikil malgache, chiromancie, cartomancie, voisinent avec des connaissances théologiques, botaniques et ethnologiques telles que celles compilées par Robert Chaudenson (1983) ; voir aussi Benoist (1993).

30. Pour une description détaillée voir ma contribution dans Samson, Lagarde et Marimoutou 2008.

31. La disparition d'une projection du maloyèr, « son esprit » selon le peintre (entretien du 11 décembre 2007), ôte tout intérêt à cette reproduction. Il réitère en outre la question, largement débattue par les acteurs du Renouveau, de la possibilité 
(en particulier celles directement liées aux ancêtres : nettoyage des boukan, confection des décorations pour les sèrvis, émotion chantée, analyse du maloya, etc.). Soumises à l'appréciation constante du regard omniscient des ancêtres, toutes demandaient le meilleur de moi. Les habitués des cultes, y compris dans le sud de l'île, commençaient du reste à me trouver du sang et des ancêtres malgaches, notamment suite à la réponse positive que Madame Baba donna à mon invitation de traverser l'île pour assister au service de Madame Yvonne.

Suite à cette lente dépossession, tout d'abord consentie, d'un moimême disons «Zorey », et face au désintérêt de ses sept enfants pour la reprise des affaires religieuses trop exigeantes de leur mère, Madame Yvonne insinua de plus en plus qu'étant donné mon intérêt, « le don irait peut-être sur moi à sa mort ». Je compris alors que j'avais fait fausse route. Ou plutôt je compris où menait un respect naïf de cette culture minorée. Car, comme j'en pris conscience avec deux rêves - activité majeure de la vie des esprits - faits les 31 octobre et $1^{\text {er }}$ novembre 2007 chez Madame Yvonne, $\mathrm{j}$ 'avais investi dans mon terrain les structures inconscientes issues de mon milieu d'origine. Matrifocal à sa façon, en cela que l'homme en est plutôt absent et que les femmes (mon bann monmon à moi) y incarnent l'autorité (culturelle, familiale, domestique, religieuse) ${ }^{32}$, ce dernier dénote un contrôle et une rigidité principielle liés au passé le plus lointain et à la nécessité d'y rester fidèle, taisant au besoin les conflits pouvant le mettre en péril, fragilisé qu'il se trouve en situation subalterne face aux normes sociales dominantes. De telle façon put alors s'activer en moi la reviviscence d'une culpabilité due au fait de ne plus vivre dans le droit fil d'une culture familiale, sinon païenne, du moins paysanne, située à mille lieues de cette ontologie naturaliste décrite par Descola (2005) qui avait décrété viable l'esclavage et qui, engendrant l'industrieuse modernité ${ }^{33}$, réduit chaque jour un peu plus les chances d'un vécu harmonieux entre notre espèce et les étants non-humains, à commencer par notre mère à tous, la Terre.

Outre la confusion liée à la toxicité de certains rapports engendrés parfois par des contextes tels (Mulot 2013), c'est de l'homologie entre deux mondes incarnés par deux personnes (ma grand-mère et Madame Yvonne),

du passage entre sphère sacrée et sphère profane dont l'image et le son restent les véhicules majeurs.

32. C'est ce que me semblait signifier en concert Marie-Christine Salem lorsqu'elle prononcait parfois « fonm » en présentant son dernier album rendant hommage à sa mère (Salem Tradition 2005).

33. La « Modernityé » (« le moderne il tue ») selon un jeu de mot kréol du fameux groupe de maloya électrique Ousanousava (2002:\#7). 
de leurs ressemblances profondes issues de passés disjoints mais tous deux « en conserve », qu'est né ce cas d'emprise psychologique corollaire de ma « réunionnisation ». Précisément, à partir de lui, j'ai pu comprendre combien la définition des liens de parenté est décisive parmi les Créoles et en particulier les descendants d'esclaves ou d'engagés africains et malgaches. Combien le maloya, la nourriture et le sexe font système dans un univers malade, clos, verrouillé. Un univers qu'il s'agit de pénétrer et d'ouvrir jusqu'à le changer. D'y « rayonner » en séduisant, par exemple, toujours plus d'auditeurs se tenant à portée d'ouïe et donc susceptibles de rentrer dans le rond, de goûter au sacré par le chant, le jeu, la danse étant entendu qu'ils ont en partage un même sang - assurément bâtard -, celui que pompait déjà le cœur des premiers sapiens marchant, comme chacun le sait, dans les savanes du berceau de l'humanité.

\section{Emphase identitaire}

Un autre mécanisme de la créolisation apparut dans le processus de « déprise » que j'entamai alors vis-à-vis d'une situation ayant pris une tournure négative, à peine exprimées mes réticences envers une transmission devenue plus mystique que scientifique. Accompagné par d'autres connaisseurs des affaires religieuses et sorcières de leur île-lesquels me confirmèrent combien ma famille n'avait jamais eu de lien avec ces deux « religions du sang » que sont les cultes « malgaches » ou malbar ${ }^{34}$ et donc combien je dépendais plutôt de mes croyances catholiques, notamment de la figure maternelle de la Vierge Marie dont j'avais gardé durant tout mon doctorat une médaille, offerte par ma mère, autour du cou-, je pus commencer d'expérimenter une certaine « emphase identitaire ». Celle-ci consiste à approfondir sa propre identité de départ une fois entré en relation intime avec une ou plusieurs autres. Le nouveau contenant identitaire en assume ainsi mieux le caractère nécessairement cumulatif et pluriel de cette nouvelle individuation. C'est ce qu'explique à sa façon selon moi Jacqueline Andoche dans un effort réflexif exemplaire (1996) rappelant au passage combien ce sont les individus plutôt que les cultures qui se rencontrent.

À l'instar du proverbe kréol « quand tu ne sais plus où tu vas, regarde d'où tu viens ${ }^{35}$, les aléas de la vie nous somment de refaire surface en nous retournant sur nos acquis. C'est ce que firent, en sauvant ce qu'ils purent

34. Le sang en question n'est donc pas que celui des animaux sacrifiés par ces deux branches de la religion créole.

35. Lequel a été reformulé positivement par Lindigo : «Kan ou koné oussa ou sort', ou koné oussa ou sava » $(2008: \# 1)$. 
de la musique et des usages symboliques de leurs ancêtres, les transbordés de toutes nasyon dans les ports de traite, à bord des vaisseaux négriers ou sur les plantations où on les dispersait. C'est ce que continuent de faire les identités au fil de leur entrée en relation et de leurs perpétuelles redéfinitions. C'est ce que j'entamai au sortir de chez Madame Yvonne en achetant non plus du maloya mais All Things Must Pass (Harrison 2001), vaste triplealbum particulièrement inspiré du plus religieux, et du plus discret, des Beatles. Devenu désormais la figure symbolique qui me redonna accès à des sonorités anglophones de ma jeunesse ainsi que le désir d'enregistrer un jour mes propres compositions (ce qui se concrétisa six ans plus tard alors que ma vie s'orientait hors de l'université), nul doute qu'Harrison représente pour moi, et possiblement pour bien d'autres, une référence historique et esthétique homologue à ce parrainage qu'inspirent les granmoun nés avant 1946 ou les artistes contemporains à leurs très créatifs continuateurs réunionnais. De ceux qui justifient telle ou telle reprise (cover dit-on en anglais) par exemple. Certes, bien plus lâche et bien moindrement émotif, ce type de lien façonné par le marché musical international semble, lui aussi, engendrer des stars et des demi-dieux...

Comme la «schismogenèse » chez Bateson ou le "principe de coupure » chez Bastide (1960 : 392), lequel reconnaissait d'ailleurs qu'on échange plus en temps de guerre que de paix, les oppositions inhérentes relatives aux religions créolisées (Dumas-Champion 2010), aux différentes manières d'effectuer les cultes familiaux rendus aux ancêtres kréol kaf malgas, aux traditions régionales du maloya ${ }^{36}$, aux scènes des maloyas " traditionnels » et "électriques", à celles du maloya et du séga, aux cultures métropolitaine et réunionnaise, aux lotoise et aveyronnaise (etc...) permettent, à chaque fois, de s'approprier, à condition de les approfondir, des conceptions qui, pour différenciées et polarisées dans le traitement dont elles font l'objet ici et là, n'en rendent pas moins évident leur caractère universel et commun. Bien que souvent abordée comme marginale dans un monde volontiers divisé ${ }^{37}$, c'est d'une telle convergence que nous entretiennent les sociétés

36. L'analyse du maloya dans l'ensemble de l'île permet de dégager au moins deux types de cultes kréol kaf malgas qui participent à la production de deux types de scènes du maloya traditionnel (Lagarde 2008). De ce fait, l'œuvre de Dumas-Champion, aussi majeure soit-elle, semble manquer en partie son objet (Lagarde 2013).

37. Comme l'a résumé Jean Benoist, « [l]e métis, l'incertain, l'entre deux races, l'entre deux langues, l'entre deux familles, l'entre deux cultes, c'est l'opposé de toutes normes à la fois : celles de la rationalité occidentale, de la morale chrétienne, de la structure linguistique la plus explicite, des modèles familiaux tels que les prônent toutes les sociétés. On est à la marge. C'est là qu'on a son centre : la marge » (Lévy 1999 : 149). 
créoles susceptibles de dépasser les cloisonnements - et en tout premiers lieux ceux dits raciaux (Bonniol 2013) - pour relier les segments sociaux les plus divers une fois (ré)entendue leur unité fondamentale au sein d'un continuum aussi vaste que l'est notre culture devenue mondiale. Fût-ce en essayant, plus ou moins adroitement, de faire de nous des captifs ; ce à quoi parviennent du reste si communément les musiques que nous jugeons bonnes à nos oreilles et dont un effet majeur, à bien suivre les Réunionnais, est de nous aider à habiter cette vie avec vigueur tout en rendant grâce, collectivement si possible. 


\section{Références}

Andoche, Jacqueline, 1996, «Il était une fois... une ethnographe, sa société (l'île de La Réunion), des secrets, des sorts : histoire d'une rencontre avec soi-même ». Nouvelle Revue d'Ethnopsychiatrie 29:91-113.

Bastide, Roger, 1960, Les religions africaines du Brésil. Vers une sociologie des interpénétrations de civilisations. Paris, PUF.

Bateson, Gregory, 1971 [1936], La cérémonie du Naven. Paris, Éditions de Minuit.

Benoist, Jean, 1984, « Paysans de la Réunion ». Annuaire des pays de l'océan Indien $8: 145-240$.

1993, Anthropologie médicale en société créole. Paris, PUF.

, 1998, Hindouismes créoles. Mascareignes, Antilles. Paris, Éditions du CTHS.

Blacking, John, 1973, Le sens musical. Paris, Éditions de Minuit.

Boilès, Charles et Jean-Jacques Nattiez, 1977, « Petite histoire critique de l'ethnomusicologie ». Musique en jeu 28 : 26-54.

Bonniol, Jean-Luc, 2013, «Au prisme de la créolisation. Tentative d'épuisement d'un concept ». L'Homme 207-208 : 237-288.

Bourdieu, Pierre, 2004, Esquisse pour une auto-analyse. Paris, Raisons d'agir. , 2013, Manet, une révolution symbolique. Paris, Raisons d'agir/Seuil.

Boyer, Henri, 1991, Éléments de sociolinguistique. Langue, communication et société. Paris, Dunod.

Chanson, Philippe, 2011, Variations métisses. Dix métaphores pour penser le métissage. Louvain-la-Neuve, Bruylant-Academia.

Chaudenson, Robert, 1983, Magie et sorcellerie à La Réunion. Saint-Denis, Livres Réunion.

Clifford, James, 1996, Malaise dans la culture. L'ethnographie, la littérature et l'art au XXe siècle. Paris, École nationale supérieure des Beaux-Arts.

Descola, Philippe, 2005, Par-delà nature et culture. Paris, Gallimard.

Desroches, Monique, 1996, Tambours des dieux. Montréal et Paris, L'Harmattan.

Desrosiers, Brigitte, 1996, « Le discours sur la musique, le discours sur l'identité à la Réunion ». Travaux $\mathcal{E}$ Documents $8: 29-47$.

Dumas-Champion, Françoise, 2010, «Un sacrifice sous influence. Étude comparative du sacrifice hindou et malgache à La Réunion ». Incidence $6: 269-292$

Favret-Saada, Jeanne, 2004 [1977], Les mots, la mort, les sorts. La sorcellerie dans le Bocage. Paris, Gallimard.

Freyre, Gilberto, 1974 [1933], Maîtres et esclaves. La formation de la société brésilienne. Paris, Gallimard. 
Geertz, Clifford, 1998, «La description dense. Vers une théorie interprétative de la culture ». Enquête $6:$ 73-105.

Ghasarian, Christian, 1996, Introduction à l'étude de la parenté. Paris, Seuil. , 1998, «À propos des épistémologies postmodernes ». Ethnologie française 28 (4) : 563-577.

—_ 2002, «Sur les chemins de l'ethnographie réflexive ». Dans Christian Ghasarian (dir.), De l'ethnographie à l'anthropologie réflexive : 5-33. Paris, Armand Colin.

Green, Anne-Marie, 2000, «Les enjeux méthodologiques d'une approche sociologique des faits musicaux ». Dans Anne-Marie Green (dir.), Musique et sociologie. Enjeux méthodologiques et approches empiriques : 17-40. Paris, L'Harmattan.

_ 2003, « Le fait musical total ou la connaissance sociologique du musical contemporain ». Dans Monique Desroches et Ghyslaine Guertin (dir.), Construire le savoir musical. Enjeux épistémologiques, esthétiques et sociaux : 219-231. Paris, L'Harmattan.

Hoggart, Richard, 1991, 33 Newport Street. Autobiographie d'un intellectuel issu des classes populaires anglaises. Paris, Gallimard/Seuil.

Jamin, Jean, 1985, « Le texte ethnographique. Argument ». Études rurales 97-98:13-24.

Lagarde, Benjamin, 2004, "Lieux des boire. Une adolescence figeacoise ». Quercy Recherche 115 : 57-59.

_, 2008 , «Du lontan au koméla: deux disques de maloya pour un avenir réunionnais ». Faire Savoirs 7 : 93-98.

, 2011, « Le maloya, entre religions populaires et nouveaux syncrétismes ». Dans Valérie Aubourg (dir.), Religions populaires et nouveaux syncrétismes. Actes du colloque international de Saint-Denis des 14 et 15 mai 2009 : 85-99. Sainte-Clotilde, Université de La Réunion/ Surya éditions.

, 2012, Réunion maloya. La créolisation réunionnaise telle qu'entendue depuis sa musique traditionnelle. Thèse d'anthropologie, Université AixMarseille.

_ , 2013, «Françoise Dumas-Champion. Le mariage des cultures à l'île de La Réunion ». L'Homme 207-208 : 369-372.

Latour, Bruno, 1996, Petite réflexion sur le culte moderne des dieux faitiches. Le Plessis-Robinson, Les Empêcheurs de penser en rond.

Léger, Fabrice, 2001, Le maloya : 1960-1970. Le combat culturel d'une musique, étude de sources orales. Mémoire de maîtrise d'histoire, Université de La Réunion.

Leiris, Michel, 1996, Miroir de l'Afrique. Paris, Gallimard. 
Le Roy Ladurie, Emmanuel, 1977, « Du bon usage du Rouergue ». Dans Bernard Dufour, La pierre et le seigle : 5-25. Paris, Seuil.

Les Inrockuptibles, 2016, « La bibliothèque rock idéale ». Hors série : 26-27.

Lévy, Joseph-Jean, 2000, Entre les corps et les dieux. Entretiens avec Jean Benoist. Montréal, Liber.

Morin, Françoise, 1975, « Roger Bastide ou l'anthropologie des gouffres ». Archives en sciences sociales des religions $40: 99-106$.

Mulot, Stéphanie, 2013, «La matrifocalité caribéenne n'est pas un mirage créole ». L'Homme 207-208: 159-192.

Nicole, Rose-May, 1996, Noirs, Cafres et Créoles. Étude de la représentation du non-blanc réunionnais. Documents et littératures réunionnaises (17101980). Paris, L'Harmattan.

Olivier de Sardan, Jean-Pierre, 1995, « La politique du terrain. Sur la production des données en anthropologie ». Enquête 1 : 71-109.

_ 2000, «Le "Je" méthodologique. Implication et explicitation dans l'enquête de terrain ». Revue française de sociologie 47 (3) : 417-445.

Ottino, Paul, 1999, "Quelques réflexions sur les milieux créoles réunionnais ». Dans Bernard Chérubini (dir.), La recherche anthropologique à La Réunion. Vingt années de travaux et de coopération régionale : 65-95. Paris, L'Harmattan.

Poirier, Jean et Sudel Fuma, 2004, «La mémoire de l'esclave. Survivances et permanences ». Dans Sudel Fuma (dir.), Mémoire orale de l'esclavage dans les îles du Sud-Ouest de l'océan Indien : silences, oublis et reconnaissance: 37-54. Saint-Denis, Université de La Réunion/Océan éditions.

Saïd, Edward, 2003 [1978], L'orientalisme. L'Orient créé par l'Occident. Paris, Seuil.

Samson, Guillaume, 2006, Musique et identité à La Réunion. Généalogie des constructions d'une singularité musicale insulaire. Thèse de doctorat d'anthropologie et de musique, Université Paul Cézanne (Marseille) et Université de Montréal.

Samson, Guillaume, Benjamin Lagarde et Carpanin Marimoutou, 2008, L'univers du maloya. Histoire, ethnographie, littérature. Sainte-Clothilde, Éditions de la DREOI.

Vergès, Françoise, 1999, Monsters and revolutionnaries. Colonial family romance and métissage. Durham et Londres, Duke University Press.

Vergès, Paul et Brigitte Croisier, 1993, D’une île au monde. Entretiens. Paris, L'Harmattan.

Winkin, Yves, 1988, «Erving Goffman. Portrait du sociologue en jeune homme ». Dans Erving Goffman, Les moments et leurs hommes : 11-92. Paris, Seuil/Minuit. 
Wolff, Eliane, 1991, Quartiers de vie. Approche ethnologique des populations défavorisées de l'île de La Réunion. Paris, Méridiens Klincksieck.

Discographie et filmographie

Bourbon maloya. Musique traditionnelle de l'île de La Réunion, 1999. 3CD, Les Chokas/Oasis.

Dumas-Champion, Françoise, 2003, Service 40 jours. Transmission des esprits après un décès (île de la Réunion). 65', numérique, Paris, CNRS/UMR 8048.

France: une anthologie des musiques traditionnelles, 2010, vol. 9, France d'Outre-mer. Enregistrements réalisés entre 1962 et 2007. CD, Frémeaux et Associés.

Granmoun Lélé, 1998, Dan kèr Lélé. CD, Label bleu/Indigo.

Harrison, George, 2001 [1970], All Things Must Pass. 2CD, Gnome Records. Lindigo, 2008, Lafrikindmada. CD, Cobalt.

Ousanousava, 2002, Lé kool! CD, Oasis productions.

Rouquier, Georges, 1946, Farrebique (ou les quatre saisons). 90', DVD, Crucial Films.

—, 1984, Biquefarre. 90', DVD, Crucial Films.

Salem Tradition, 2005, Fanm. CD, Cobalt.

Urbain Philéas, 2001, Lo flambo. CD, Oasis/Les Chokas.

—, 2003, Dé langaz maloya. CD, Oasis/Les Chokas.

—_, 2008, Rano Manogoabé. CD, Oasis.

_, 2011, Fiamboniany. CD, Oasis.

Viry, Firmin, 1976, Firmin Viry, le maloya et le VI e Congrès du Parti Communiste Réunionnais. 33 tours, Document $n^{\circ} 1$.

__, 1999, Île de La Réunion. Le Maloya. Firmin Viry. CD, Ocora/ Radio France.

Waro, Danyèl, 1994, Batarsité. CD, Piros. , 2013, Kabar. CD, Cobalt. 